\title{
Hypercholesterolaemia and diabetes mellitus
}

\author{
J. N. HARRIS-JONES AND D. J. WARD \\ From the General Hospital, Llanelly, and the Royal Hospital, Sheffield
}

SYNOPSIS An association of essential hypercholesterolaemia and diabetes mellitus is postulated. Case records are included to illustrate hypercholesterolaemia secondary to acute diabetes mellitus, and essential hypercholesterolaemia, independent of, but accompanying diabetes mellitus. Whereas in the former the serum cholesterol returns to normal and its attendant clinical manifestations resolve when the diabetes is controlled, this is not so in the latter type.

Evidence is presented to show that impaired carbohydrate tolerance is not a feature of essential hypercholesterolaemia.

Abnormalities of lipid metabolism associated with uncontrolled diabetes mellitus have been assumed to be secondary to the disordered carbohydrate metabolism, an assumption apparently confirmed by the fall in serum cholesterol which usually accompanies control of the diabetes mellitus (Thannhauser, 1950; Haymond and Berry, 1954). Observations on diabetic children in fair or good diabetic control showed that mean serum levels of $\beta$ lipoproteins and cholesterol were significantly higher in the children with blood sugar levels above $200 \mathrm{mg}$. per $100 \mathrm{ml}$. than in those with blood sugars below this figure (Wolff and Salt, 1958).

Failure of an elevated serum cholesterol level to return to normal when diabetic control has been established has been stated to be of serious prognostic importance (Cantarow and Trumper, 1955). The possibility that this continued hypercholesterolaemia may represent an independent metabolic abnormality appears to have received relatively little attention.

The case histories which follow serve to illustrate these two patterns of hypercholesterolaemia which may be encounted in patients with diabetes mellitus.

\section{CASE REPORTS}

CASE 1 A woman aged 29 years presented with one year's history of polydipsia, polyuria, lassitude, and weight loss; an augmented appetite may have resulted in a high fat intake.

Examination revealed a cutaneous xanthoma diabeticorum and very striking lipaemia retinalis. Diabetes mellitus was confirmed by the finding of heavy glycosuria with acetonuria, a fasting blood sugar of $205 \mathrm{mg}$. per $100 \mathrm{ml}$. rising to $368 \mathrm{mg}$. per $100 \mathrm{ml}$. two hours after $100 \mathrm{~g}$. glucose by mouth. The fasting serum was milk

Received for publication 1 November 1960 white in appearance and the serum cholesterol $1,458 \mathrm{mg}$. per $100 \mathrm{ml}$. Treatment with insulin resulted in a rapid clearance of the xanthomata, lipaemia retinalis, and the plasma lipaemia, the serum cholesterol falling eventually to $166 \mathrm{mg}$. per $100 \mathrm{ml}$. (Table I). This patient has been described in greater detail elsewhere (Bloom and Crowley, 1956).

\section{TABLE I}

SERUM CHOLESTEROL LEVELS IN CASES 1 AND 2 AFTER STABILIZATION WITH INSULIN

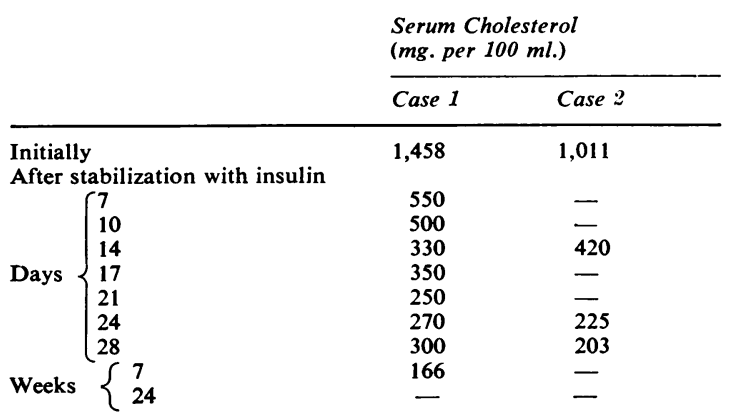

CASE 2 A youth of 17 years of age was admitted with one month's history of polydipsia, polyuria, weight loss, and weakness.

Examination showed a young man of poor nutrition with clinical dehydration. Ophthalmoscopy revealed striking lipaemia retinalis; there were no skin xanthomata.

Urine analysis showed severe glycosuria and ketonuria; the blood sugar was $350 \mathrm{mg}$. per $100 \mathrm{ml}$. The plasma was milk white and the total serum cholesterol $1,011 \mathrm{mg}$. per $100 \mathrm{ml}$. Response to insulin was prompt, the diabetic state coming under control within 48 hours; the lipaemia retinalis became rapidly less marked and the retinal vessels were normal again in about 14 days, coincident with the fall in plasma lipaemia and hypercholesterolaemia (Tables I and IA). 
TABLE IA

RESPONSE OF PLASMA LIPIDS TO INSULIN THERAPY IN CASE 2

\begin{tabular}{cccc} 
Day of Disease & Neutral Fat $(\mathrm{mg} . / 100 \mathrm{ml})$. & Cholesterol $(\mathrm{mg} . / 100 \mathrm{ml}$ ) & Phospholipids (mg./100 ml.) \\
\hline 1 & $7,858(0-200)$ & $1,011(150-300)$ & $1,217(60-350)$ \\
14 & $318(0-200)$ & $420(150-300)$ & $411(60-350)$ \\
28 & $323(0-200)$ & $225(150-300)$ & $273(60-350)$
\end{tabular}

In both patients the extreme hyperlipaemia with hypercholesterolaemia which very occasionally accompanies acute diabetes mellitus was well illustrated. Eruptive xanthomata in one and striking lipaemia retinalis in both were the main clinical signs of this metabolic abnormality. Extreme lipaemia was confidently predicted in Case 2 following routine fundus examination on admission.

The clinical signs and hypercholesterolaemia resolved promptly in both patients with control of the diabetes mellitus.

CASE 3 A woman of 65 years, complaining of pruritus vulvae, polydipsia, and polyuria, was referred to hospital for investigation. The patient had well-developed xanthoma palpebrum; there was no evidence of myxoedema, hepatic, or renal disease.

Urinary examination showed heavy glycosuria but no proteinuria. Blood sugar was $198 \mathrm{mg}$. per $100 \mathrm{ml}$. fasting and $259 \mathrm{mg}$. per $100 \mathrm{ml}$. two hours after ingestion of 50 mg. of glucose. The serum was clear and the serum cholesterol $400 \mathrm{mg}$. per $100 \mathrm{ml}$. A low calorie diet failed to control glycosuria, but the patient refused insulin.
Four years later the patient returned complaining की retrosternal pain and at this time an electrocardiogram showed a posterior myocardial infarction. She was then treated with carbutamide which controlled the diabeteह initially, but this was not accompanied by a fall in serure cholesterol.

A low fat diet, sitosterol, and finally a 'corn oil' diet. were employed in an attempt to reduce the raised serurf cholesterol (Fig. 1).

CASE 4 A woman of 59 years was referred to hospitat because of retrosternal pain on effort. Examination showed a marked corneal arcus but no other significant abnormality. The electrocardiographic tracing was com sistent with a posterior myocardial infarction.

Six months later the patient returned complaining $\overrightarrow{a b}$ thirst, polyuria, and pruritus vulvae. Urine analys $\AA_{\text {S }}$ showed glycosuria, and the fasting blood sugar was $180 \mathrm{mg}$. per $100 \mathrm{ml}$. A glucose tolerance test performeo more recently showed a blood sugar of $223 \mathrm{mg}$. per $100 \mathrm{mE}$ two hours after ingestion of $5 \mathrm{~g}$. glucose. The seruro cholesterol was $530 \mathrm{mg}$. per $100 \mathrm{ml}$.; the fasting seruri was clear.

Glycosuria was rapidly controlled by a low calor

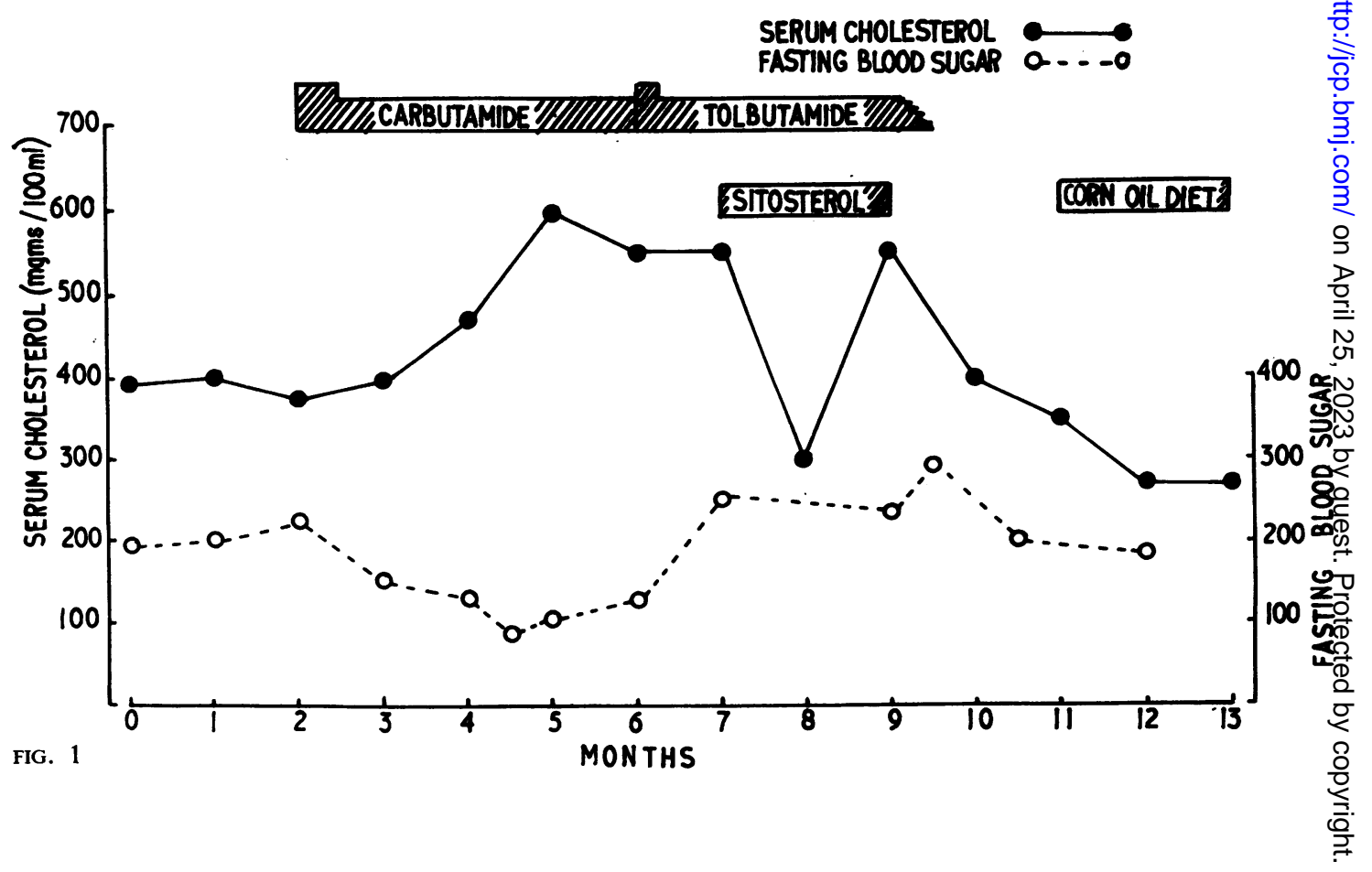




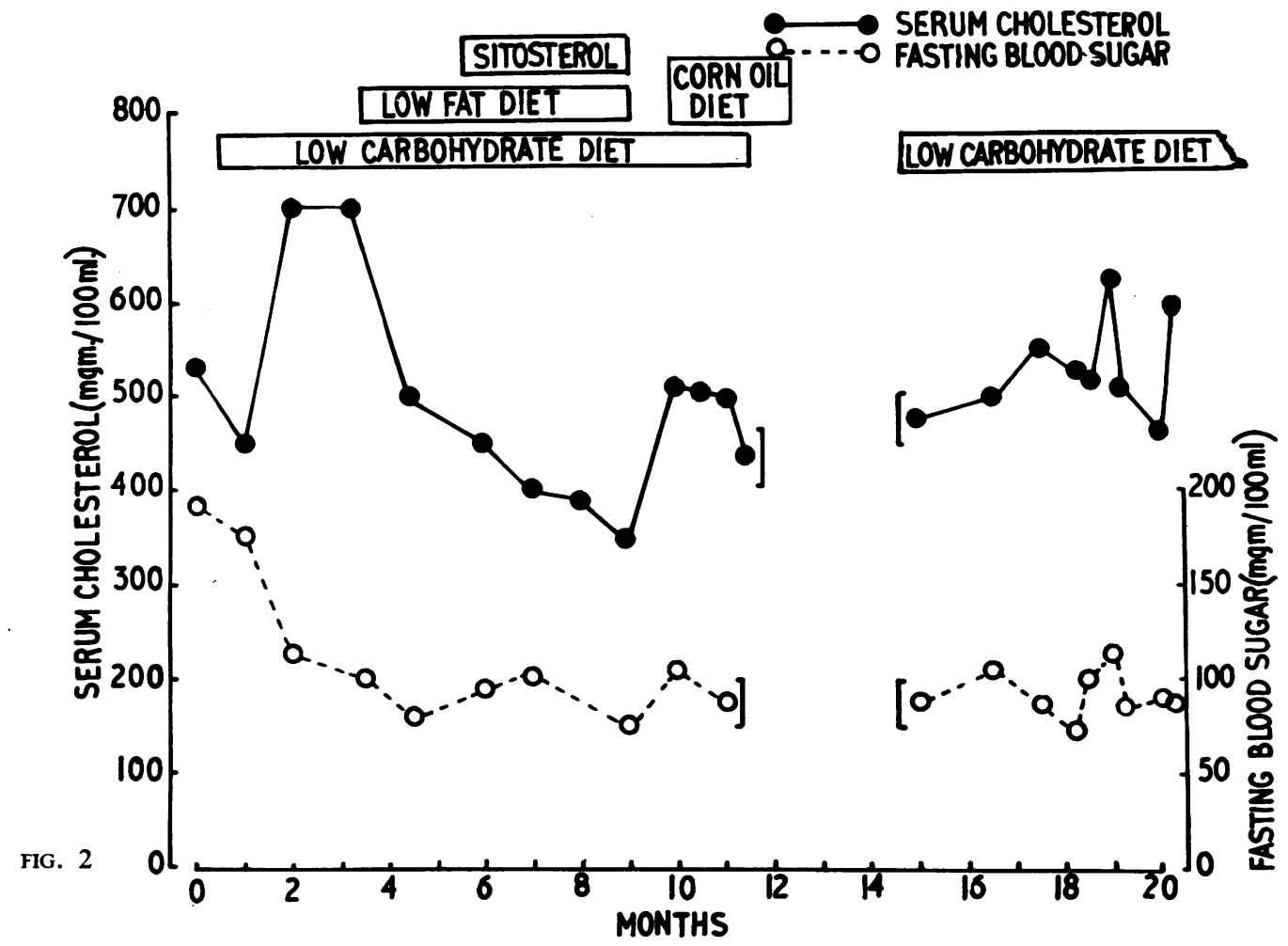

diet, but control of the diabetes was not accompanied by a fall in the serum cholesterol. A low fat diet, sitosterol, and subsequently a 'corn oil' diet were used in an unsuccessful attempt to reduce the raised serum cholesterol level (Fig. 2).

Both patients demonstrate the association of essential hypercholesterolaemia with diabetes mellitus; in each case levels of serum cholesterol were recorded which were well above those quoted as normal for the sex and age group concerned by Keys, Mickelsen, Miller, Hayes, and Todd (1950). The essential nature of this hypercholesterolaemia was supported by the presence of xanthelasma palpebrum in Case 3, which remained uninfluenced by control of the diabetes, and the presence of a marked corneal arcus in Case 4, which is not a recorded feature of secondary hypercholesterolaemia.

That these cases represented examples of essential hypercholesterolaemia and not hyperlipaemia was supported by the fact that in both the values for neutral fats and phospholipids were normal, and that in neither case was the fasting serum lactescent.

There is little evidence that impairment of carbohydrate metabolism occurs with undue frequency in essential hypercholesterolaemia. During an investigation of families with essential hypercholestero- laemia (Harris-Jones, Jones, and Wells, 1957), fasting blood sugar estimations were obtained in patients with hypercholesterolaemia and their near relatives. Whereas such fasting blood sugar levels alone cannot exclude impaired carbohydrate metabolism, they remained normal throughout a wide range of serum cholesterol levels (Fig. 3). Glucose tolerance tests, using the standard $50 \mathrm{~g}$. oral method, were performed on six patients with hypercholesterolaemic xanthomatosis, and were found to be

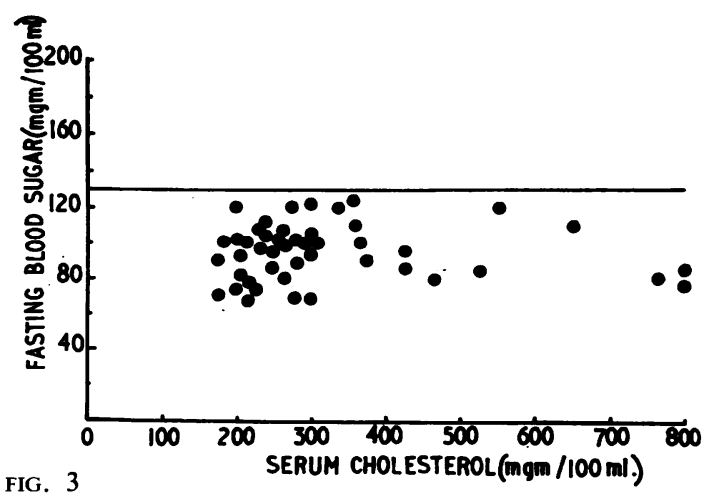




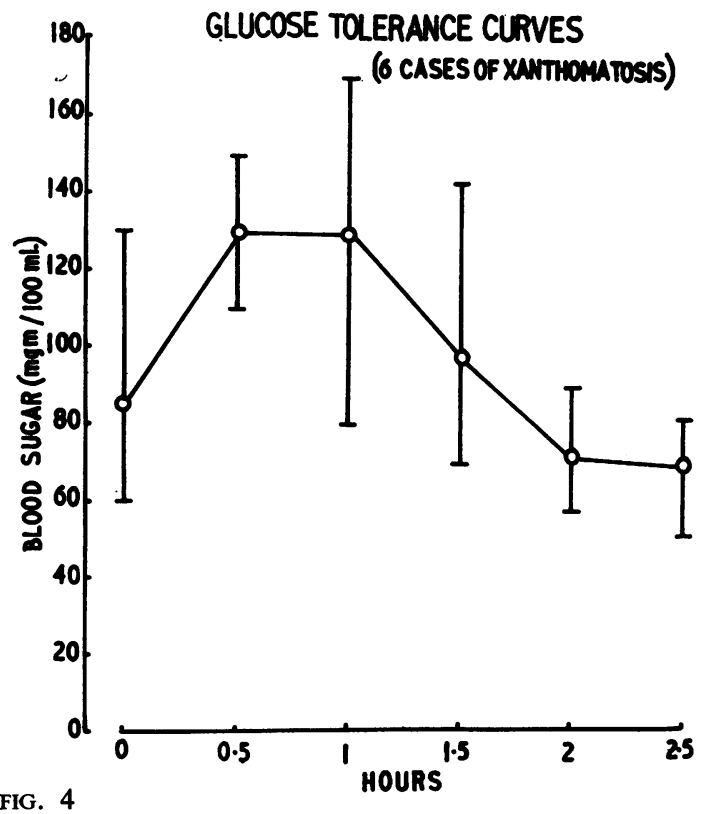

normal (Fig. 4). This is in agreement with a similar investigation by Wilkinson, Hand, and Fliegelman (1948).

\section{DISCUSSION}

Hypercholesterolaemia accompanying uncontrolled diabetes mellitus is well recognized.

Increased fatty acid metabolism consequent on insulin deficiency results in an increase in concentration of the intermediary products of fat metabolism. Therefore, an increased supply of 'acetate' becomes available for synthesis into keto-acids and cholesterol (Mookerjea and Sadhu, 1957). As would be expected, the abnormal cholesterol metabolism is modified when carbohydrate metabolism is restored towards normal by treatment. This is expressed by the resolution of skin xanthomata, and rapid fall of the serum cholesterol, which follow $\frac{\stackrel{0}{*}}{\text { stabilization of the diabetes. }}$
stion

Less is known concerning the metabolic defect responsible for essential hypercholesterolaemia. It is an inborn error of metabolism transmitted as an $\frac{\mathrm{C}}{\mathrm{O}}$ incomplete dominant trait, and detected most com- $\frac{\bar{c}}{\omega}$ monly in the middle age groups.

Inheritance of two independent metabolic defects 2 may be encountered, as illustrated by the association in of diabetes mellitus and gout (Weiss, Segaloff, and $\vec{\circ}$ Moore, 1957), or hypercholesterolaemia and hyperuricaemia (Harris-Jones, 1957). An association of $\vec{\omega}$ diabetes mellitus and hypercholesterolaemia would $\frac{\Omega}{2}$ not therefore appear improbable.

In this event one would not expect the clinical $\vec{A}$ manifestation of hypercholesterolaemia, or the $\omega$ serum cholesterol to be necessarily affected by con- $N$ trol of the diabetic state. As will be observed in Cases 3 and 4, in which the hypercholesterolaemia was considered to be an essential defect, reduction $\vec{z}$ of the fasting blood sugar was in fact associated with a rise in the serum cholesterol. No valid hypothesis can be offered for this apparent paradoxical be- $\mathscr{Q}$ haviour of the serum cholesterol.

We are greatly indebted to Dr. Arnold Bloom and Miss M. Crowley for permission to publish details of Case $1 \supset$ and for their assistance. We thank Dr. Arthur Jordan, Dr. A. L. Wells, and Dr. Joan Zilva for biochemical $\frac{\varnothing}{\varnothing}$ estimations.

\section{REFERENCES}

Bloom, A.. and Crowley, M. F. (1956). Proc. roy. Soc. Med., 49, 830. Cantarow: A., and Trumper, M. (1955). Clinical Biochemistry, 5th ed. Saunders, Philadelphia and London.

Harris-Jones, J. N. (1957). Lancet, 1, 857.

$\longrightarrow$, Jones, E. G., and Wells, P. G. (1957). Ibid, 1, 855.

Haymond, T. A., and Berry, K., Jr. (1954). Arn. intern. Med., 41, 609.

Keys, A., Mickelsen, O., Miller, E. V. O., Hayes, E. R., and Todd, R. L. (1950). J. clin. Invest., 29, 1347.

Mookerjea, S., and Sadhu, D. P. (1957). Metabolism, 6, 326.

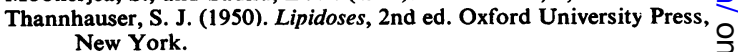

Weiss, T. E., Segaloff, A., and Moore, C. (1957). Metabolism, 6, 103. Wilkinson, C. F., Hand, E. A., and Fliegelman, M. T. (1948). Ann. O intern. Med., 29, 671.

Wolff, O. H., and Salt, H. B. (1958). Lancet, $\quad 1,707$. 